\title{
The Effects of Patients BMI on Lumbo Pelvic Parameters in Patients with Chronic Low Back Pain in Jos North Central Nigeria
}

\author{
Michael Bundepuun Ode ${ }^{1,}$,, Okpatuma Tony ${ }^{1}$, Taiwo Femi Olu ${ }^{1}$, Amupitan Idumagbodi ${ }^{1}$, \\ Ode Gloria Nengi ${ }^{2}$, Yilleng Shem Bulus ${ }^{1}$, Onche Icha Inalegwu ${ }^{1}$ \\ ${ }^{1}$ Department of Orthopaedics and Trauma, Faculty of Clinical Sciences, University of Jos, Jos, Nigeria \\ ${ }^{2}$ Department of Community Medicine, Jos University Teaching Hospital, Jos, Nigeria
}

Email address:

odemb2014@gmail.com (M. B. Ode)

${ }^{*}$ Corresponding author

\section{To cite this article:}

Michael Bundepuun Ode, Okpatuma Tony, Taiwo Femi Olu, Amupitan Idumagbodi, Ode Gloria Nengi, Yilleng Shem Bulus, Onche Icha Inalegwu. The Effects of Patients BMI on Lumbo Pelvic Parameters in Patients with Chronic Low Back Pain in Jos North Central Nigeria. Journal of Surgery. Vol. 9, No. 2, 2021, pp. 93-97. doi: 10.11648/j.js.20210902.20

Received: March 18, 2021; Accepted: March 30 2021; Published: April 13, 2021

\begin{abstract}
Introduction. The pelvic posture is defined by measurable radiologic parameters which are related to the lumbar and sacral spine. These parameters include, pelvic tilt (PT), lumbar Lordosis (LL), Sacral slope (SS), Pelvic incidence (PI) and the Lumbosacral angle (LSA) The lumbopelvic parameters in the lower back have been noticed to be altered in patients presenting with low back pain. Increased BMI has been found to be a contributing factor in the onset and course of low back pain. Increased weight especially around the trunk affects the dynamics of posturing to maintain sagittal balance. We set out to determine the extent BMI influenced the lumbopelvic parameters in patients presenting with chronic nonspecific low back pain. Methods. This was a prospective cross sectional study. There were three BMI groups; normal weight (BMI19-24.9), overweight (BMI 25-29.9) and obese (BMI $>30$ ). All subjects had standing lateral radiographs of the spine. The pelvic parameters; PI, LL PT, SS and LSA, were measured. The mean values and standard deviations of the parameters in each group was determined. Analysis of variance was used to determine differences in means The relationships between all parameters were assessed using Spearman's coefficients and statistically significant correlation coefficients were determined. The level of significance was set at $\mathrm{P}<0.05$ Results. A hundred and forty patients participated in the study. Their ages ranged from 18 to 65years. M:F 1:1.1. 31 (22.1\%) of them were of normal weight, 55 (39.3\%) of them were overweight, and 54 (38.6\%) were obese. None was underweight. The sacral slope was; $34.29 \pm 6.29$ in the normal weight group, $36.20 \pm 5.97$ in those overweight and 37.81 \pm 5.98 in the obese. $(\mathrm{P}=0.036)$. Pelvic incidence was: $51.19 \pm 6.35$ in the normal weight group, $52.55 \pm 7.37$ in those overweight and $54.43 \pm 9.23$ in the obese $(\mathrm{P}=0.176)$. Lumbar lordosis was; $40.48 \pm 8.16$ in the normal weight group, $40.35 \pm 8.06$ in those overweight and $43.17 \pm 10.92$ in the obese $(\mathrm{P}=0.032)$. The pelvic tilt was; $16.84 \pm 5.33$ in the normal weight group, $16.29 \pm 3.54$ in those overweight and $16.61 \pm 5.20$ in the obese. $(\mathrm{P}=0.862)$. The Lumbosacral Angle was $12.74 \pm 3.14$ in the normal weight group, $13.45 \pm 3.79$ in those overweight and $12.98 \pm 3.55$ in the obese. $(\mathrm{P}=0.634)$ Conclusion. Increasing BMI had a statistically significant effect on increased lumbar lordosis and sacral slope in patients with chronic low back pain. Pelvic Incidence showed an increase with increasing BMI but was not statistically significant. Pelvic tilt and lumbosacral angle did not show any relationship with BMI.
\end{abstract}

Keywords: BMI, Back Pain, Sacral Slope, Lumbar Lordosis, Pelvic Incidence

\section{Introduction}

Low back pain is a common disorder affecting a large number of people worldwide. It forms a large proportion of health care expenditure and its contribution to loss of man hours at the workplace also places additional economic burden on the society. [1-3] There are multiple causes of low back pain and even though low back pain is not a diagnosis 
but a symptom, its frequent occurrence and the constellation of pathologies that result in it make this symptom of low back pain a symptom of clinical significance. Low back pain is a fairly common complaint with a life time prevalence reported as high as $50 \%-80 \%$, [4] and a point prevalence of $11 \%$ to $39 \%$ worldwide. [2,5] The one year prevalence has been found to be above $50 \%$ in Africa with a fifth of these cases progressing to chronic low back pain which back pain lasting more than three months. [5, 6] Low back pain is a very common musculoskeletal condition and one of the major sources of debility in industrialized countries. [3] Low back pain can be described as specific or nonspecific. [3, 7] Specific low back pain is that attributable to clearly defined pathologies such as, Nerve irritation, infection, tumors, trauma etc. The nonspecific back pain constitute a large majority of low back pain complaints. [7] There is a rising prevalence of back pain from the fourth decade of life and this peaks in the elderly. [8] Low back pain can be very debilitating and can result in a reduction of quality of life and places a burden on care givers, the health care system and the economy at large. The onset and the course of low back pain is affected by multiple factors which can be personal or environmental. These include; occupational posture, Obesity, depression, job dissatisfaction, height, workplace welfare, sedentary lifestyle, stress etc. [1, 6, 9] The sagittal balance of the spine is required to keep the individual in an erect position, place the least mechanical loads on the spine and improve functionality. [10] The pelvic posture is also defined by measurable radiologic parameters which are related to the lumbar and sacral spine. These parameters include, pelvic tilt (PT), lumbar Lordosis (LL), Sacral slope (SS), Pelvic incidence (PI) and the Lumbosacral angle (LSA) The lumbo pelvic parameters in the lower back have been noticed to be altered in patients presenting with low back pain.. Abnormalities in these parameters causes abnormal posturing resulting in increased loading of the discs and other structural elements of the spine, causing greater speed of degeneration, strain on the muscle and ligamentous structures around the spine, all playing significant roles in the onset and course of low back pain. [11] Increased BMI has been found to be a contributing factor in the onset and course of degenerative spine disease and in other forms of low back pain. [1, 12] Increased weight especially around the trunk affects the dynamics of posturing and results in an increase in contact forces around the spinal unit. The alteration in the lumbopelvic parameters determine whether the forces act more on the discs and vertebral bodies (anteriorly) or on the facet joints and ligaments (posteriorly). [13-15]

Obesity is becoming a public health problem worldwide especially in industrialized countries of the west. Other parts of the world where western diets and sedentary lifestyles are becoming more prevalent have begun to experience an upsurge in patients who are overweight or obese. [16-18] The effects of the truncal load on the spine and the subsequent adjustments (compensatory mechanisms) to maintain an erect posture put a load on the intervertebral discs and spine structures, speeding up degeneration of these structures and resulting in low back pain. [19-21] We set out to determine the changes if any, and to what extent BMI played a role in the lumbopelvic parameters in patients presenting with chronic low back pain in our institution.

\section{Methodology}

This was a prospective cross sectional study carried out at the Jos University Teaching Hospital, Nigeria from April 2018 to March 2019. Patients who presented to the outpatient department with chronic nonspecific low back pain, who were Nigerian and between the age of 18 to 65years, who gave consent to participate were recruited into the study. Patients with identifiable causes of low back pain such as infection, tumors, trauma, spine, hip or lower limb deformities or those who had previous spine surgeries, were excluded from the study. Following a detailed history and thorough clinical examination of patients who met the inclusion criteria, the body mass index was then calculated. (Weight in kilograms divided by height in meters, squared). Thereafter, laboratory investigations were carried out to rule out any infections or tumors. All subjects had standing lateral radiographs of the spine. The radiograph was taken with the subject standing in a comfortable position, knees fully extended, hips in neutral position. RadiAnt DICOM Viewer 4.6.9. Was used to evaluate the images and from which the lumbo pelvic parameters (Pelvic incidence, lumbar lordosis pelvic tilt, sacral slope and lumbo sacral angle) were measured. Data collected from the study was entered into a worksheet and analyzed. The mean values and standard deviations of the parameters in each group was determined. Analysis of variance was used to determine differences in means. The relationships between all parameters were assessed using Spearman's coefficients and statistically significant correlation coefficients were determined. The level of significance was set at $P<0.05$. The statistical analysis was carried out with use of the SPSS for windows program (version 23.0; SPSS Inc., Chicago, Illinois).

\section{Results}

A total of 140 subjects with chronic nonspecific low back pain who satisfied the inclusion criteria were included in the study. The mean duration of low back pain amongst the subjects was $31.4 \pm 21.9$ months (range: $3-144$ months). Their ages ranged from 18 to 65 years. $51(37.1 \%)$ of them fell within the age group 51- 60 years. $97(82 \%)$ of the patients assessed were above 40 years. Table 1 The male female ratio was $\mathrm{M}: \mathrm{F} 1: 1.1 .31(22.1 \%)$ of them were of normal weight (BMI $19-24.9), 55(39.3 \%)$ of them were overweight (BMI 25- 29.9), and 54 (38.6\%) were obese (BMI 30 and above). None was underweight. Figure 1 The occupational distribution noticed was; civil servants 36 $(25.7 \%)$, the farmers $22(15.7 \%)$, traders $16(11.4 \%)$, teachers $15(10.7 \%)$, artisans $13(9.3 \%)$, housewives $11(7.9 \%)$ and others $6(4.3 \%)$. Table 2 The sacral slope was; $34.29 \pm 6.29$ in the normal weight group, $36.20 \pm 5.97$ in the overweight 
group and $37.81 \pm 5.98$ in the obese group. $(\mathrm{P}=0.036)$. Table 3 Pelvic incidence was: $51.19 \pm 6.35$ in the normal weight group, $52.55 \pm 7.37$ in the overweight group and $54.43 \pm 9.23$ in the obese group $(\mathrm{P}=0.176)$. Table 4 Lumbar lordosis was; $40.48 \pm 8.16$ in the normal weight group, $40.35 \pm 8.06$ in the overweight group and $43.17 \pm 10.92$ in the obese group $(\mathrm{P}=0.032)$. Table 5 The pelvic tilt was; $16.84 \pm 5.33$ in the normal weight group, $16.29 \pm 3.54$ in the overweight group and $16.61 \pm 5.20$ in the obese group $(\mathrm{P}=0.862)$. Table 6 The Lumbosacral Angle was $12.74 \pm 3.14$ in the normal weight group, $13.45 \pm 3.79$ in the overweight group and $12.98 \pm 3.55$ in the obese group $(\mathrm{P}=0.634)$. Table 7 .

Table 1. Age distribution of the study participants.

\begin{tabular}{lll}
\hline Variable & Frequency & Percentage \\
\hline Age group (years) & & \\
$\leq 30$ & 14 & 10.0 \\
$31-40$ & 11 & 7.9 \\
$41-50$ & 46 & 32.9 \\
$51-60$ & 51 & 37.1 \\
$>60$ & 17 & 12.1 \\
Total & 140 & 100.0 \\
\hline
\end{tabular}

Table 2. Occupational distribution of the study participants.

\begin{tabular}{lll}
\hline Variable & Frequency & Percentage \\
\hline Occupation & & \\
Student & 11 & 7.9 \\
Civil servant & 36 & 25.7 \\
Farmer & 22 & 15.7 \\
Teacher & 15 & 10.7 \\
Artisan & 13 & 9.3 \\
Housewife & 11 & 7.9 \\
Retiree & 10 & 7.1 \\
Business & 16 & 11.4 \\
Others & 6 & 4.3 \\
Total & 140 & 100.0 \\
\hline
\end{tabular}

Table 3. Relationship between BMI and Sacral Slope.

\begin{tabular}{lllll}
\hline Variable & BMI & $($ Mean \pm SD) & F & P \\
\hline Sacral Slope & Normal & $34.29 \pm 6.29$ & 3.399 & 0.036 \\
& Overweight & $36.20 \pm 5.97$ & & \\
& Obese & $37.81 \pm 5.98$ & & \\
& Total & $36.40 \pm 6.15$ & & \\
\hline
\end{tabular}

Table 4. Relationship between BMI and Pelvic Incidence.

\begin{tabular}{lllll}
\hline Variable & BMI & $($ Mean \pm SD) & F & P \\
\hline Pelvic Incidence & Normal & $51.19 \pm 6.35$ & 1.759 & 0.176 \\
& Overweight & $52.55 \pm 7.37$ & & \\
& Obese & $54.43 \pm 9.23$ & & \\
& Total & $52.97 \pm 7.99$ & & \\
\hline
\end{tabular}

Table 5. Relationship between BMI and Lumbar Lordosis.

\begin{tabular}{lllll}
\hline Variable & BMI & $($ Mean \pm SD) & F & P \\
\hline Lumbar Lordosis & Normal & $40.48 \pm 8.16$ & 3.478 & 0.032 \\
& Overweight & $40.35 \pm 8.06$ & & \\
& Obese & $43.17 \pm 10.92$ & & \\
& Total & $41.46 \pm 9.32$ & & \\
\hline
\end{tabular}

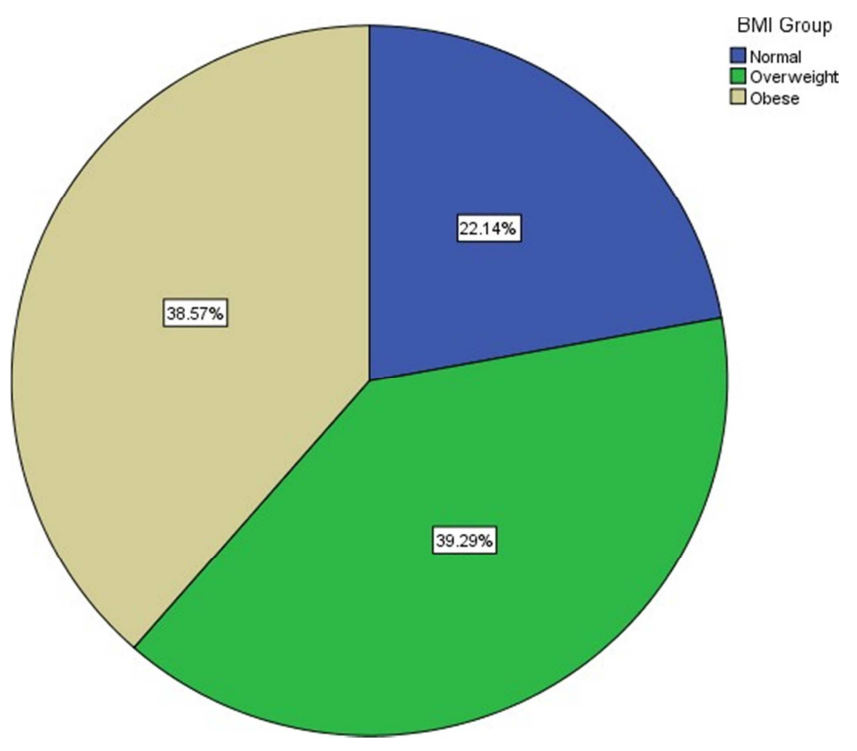

Figure 1. BMI distribution.

Table 6. Relationship between BMI and Pelvic Tilt.

\begin{tabular}{lllll}
\hline Variable & BMI & $($ Mean \pm SD) & F & P \\
\hline Pelvic Tilt & Normal & $16.84 \pm 5.33$ & 0.149 & 0.862 \\
& Overweight & $16.29 \pm 3.54$ & & \\
& Obese & $16.61 \pm 5.20$ & & \\
& Total & $16.54 \pm 4.63$ & & \\
\hline
\end{tabular}

Table 7. Relationship between BMI and Lumbosacral Angle.

\begin{tabular}{lllll}
\hline Variable & BMI & (Mean \pm SD) & F & P \\
\hline Lumbosacral Angle & Normal & $12.74 \pm 3.14$ & 0.458 & 0.634 \\
& Overweight & $13.45 \pm 3.79$ & & \\
& Obese & $12.98 \pm 3.55$ & & \\
& Total & $13.11 \pm 3.55$ & & \\
\hline
\end{tabular}

\section{Discussion}

The patients who presented with chronic nonspecific low back pain were noticed to be mostly within the age group 51 to 60 years. Other studies have shown the occurrence of chronic low back pain in advanced age with mean ages of around 70 years. $[8,22] .37 .1 \%$ of those with low back pain in this study fell within the age group of 51 to 60 years of age the most commonly occurring age group. Those above 40 years of age made up $82 \%$ of the study group. The degenerative processes that result in low back pain occurs over time and thus it is not surprising that the older patients are those manifesting with chronic low back pain. In the younger population, back pain tends to be an acute occurrence with symptoms appearing and disappearing within short periods. Also the younger age group tend to present with specific causes of low back pain. The age range of most of the patients is also associated with the age where most people tend to lead a sedentary life style. They are more highly placed in their work places or may have retired from active jobs and now lead less active lives. Sedentary life style has been implicated as an associated factor in obesity and consequently low back pain. This age group is also when a lot of people tend to put on weight and may become 
overweight or obese,[17] which also has been associated with repositioning of the trunk to maintain a balanced position and may result in increased loading of the intervertebral discs and the spinal elements resulting in degeneration of these spinal structures and the resultant occurrence of low back pain in such people. [8, 21, 22] There was a slight female preponderance in our study M:F 1:1.1. Erick PN. et al had a female preponderance in their study and showed a positive correlation with female gender and low back pain. [23] Tella BA et al in their study on prevalence of low back pain in South west Nigeria, demonstrated a male preponderance.(6). $77.9 \%$ of those studied had a BMI of over 25 with $38.6 \%$ of the study population being obese (BMI greater than 30). Obesity has been associated with an onset of low back pain and has been shown to alter the course of low back pain, has an adverse effect on patients with low back pain, and affect treatment in patients undergoing non operative or operative treatments for low back pain conditions. [12, 20, 22, 24, 25] Obesity has been noticed to be on the rise worldwide and particularly in the west and in countries who are embracing more westernized diets and whose lifestyles are becoming more sedentary. [17, 18]. Low back pain is among the leading causes of disability adjusted life years (DALYs) in patients with a high BMI. [26]

From the pelvic parameters evaluated, Lumbar lordosis was; $40.48 \pm 8.16$ in the normal weight group, $40.35 \pm 8.06$ in the overweight group and $43.17 \pm 10.92$ in the obese group $(\mathrm{P}=0.032)$. This showed a statistically significant change between the groups as weight increased. This is similar to other investigators who have noticed an increasing lumbar lordosis with weight increase. [13, 27]. This increase in lumbar lordosis noticed in obese patients with low back pain is believed to be a compensatory adjustment to maintain a balanced posture. Other investigators found a linear relationship of Body adipose index (BAI) with increasing lumbar lordisis. [22] Canbek et al in their study had a mean lumbar lordisis of $48.27 \pm 18.06$, but found no statistically significant change in lumbar lordosis across various BMI groups. [8] Other studies found a reduced lumbar lordosis with increasing weight. [28] The sacral slope was; $34.29 \pm 6.29$ in the normal weight group, $36.20 \pm 5.97$ in the overweight group and $37.81 \pm 5.98$ in the obese group. $(\mathrm{P}=0.036)$. There was a steady increase in the sacral slope over the increasing BMI categories that was statistically significant. Other researchers have also found an increasing sacral slope with increasing weight. [27, 29] An increase in sacral slope alters the relationship between the scarum and lumbar vertebrae and in patients with obesity. This has been related to an increase in spondylolisthesis in such patients. [29] We found the pelvic incidence higher with an increase in the BMI over the various groups but not statistically significant. Pelvic incidence was largely believed to be maintained in an individual over a period and even with other changing parameters. However, some studies have shown that Pelvic Incidence (PI) may change with age, posture or increased body weight. [15, 29] as demonstrated in our findings. The pelvic tilt and the lumbosacral angle did not show any pattern between the various BMI groups. Onyemachi, NO. et al in their study found a significant correlation between BMI and lumbosacral angle. [27] Civil servants and farmers were the commonest professions noted $25.7 \%$ and $15.7 \%$ respectively. Sedentary life style and the occupational posture of peasant farmers in our environment have all been implicated in the aetiology and course of chronic low back pain. $[6,9]$

\section{Conclusion}

Increasing BMI had a statistically significant effect on increasing lumbar lordosis and sacral slope in patients with chronic low back pain in this study. Majority of the patients diagnosed with chronic low back pain in this study were elderly and either overweight or obese.. Even though Pelvic Incidence showed an increase with increasing BMI this change was not significant. Pelvic tilt and lumbosacral angle did not show any relationship with increasing BMI. The findings suggest that increased weight may impact the onset and course of chronic low back pain.

\section{Declaration of Patient Consent}

Consent was sought for and obtained, with the assurances of the identity of the patients being protected.

\section{Financial Support}

No financial support was gotten.

\section{Conflict of Interest}

The authors have no conflict of interest to declare.

\section{References}

[1] Casiano VE, Dydyk AM, Varacallo M. Back Pain. StatPearls. Treasure Island (FL) 2021.

[2] Hoy D, Bain C, Williams G, March L, Brooks P, Blyth F, et al. A systematic review of the global prevalence of low back pain. Arthritis and rheumatism. 2012; 64 (6): 2028-37.

[3] Hartvigsen J, Hancock MJ, Kongsted A, Louw Q, Ferreira ML, Genevay S, et al. What low back pain is and why we need to pay attention. Lancet. 2018; 391 (10137): 2356-67.

[4] Kahere M, Ginindza T. Mapping evidence on the prevalence, incidence, risk factors and cost associated with chronic low back pain among adults in Sub-Saharan Africa: a systematic scoping review protocol. Systematic reviews. 2020; 9 (1): 57.

[5] Morris LD, Daniels KJ, Ganguli B, Louw QA. An update on the prevalence of low back pain in Africa: a systematic review and meta-analyses. BMC musculoskeletal disorders. 2018; 19 (1): 196.

[6] Tella BA, Akinbo SR, Asafa SA, Gbiri CA. Prevalence and impacts of low back pain among peasant farmers in southwest Nigeria. International journal of occupational medicine and environmental health. 2013; 26 (4): 621-7. 
[7] Kahere M, Ginindza T. The burden of non-specific chronic low back pain among adults in KwaZulu-Natal, South Africa: a protocol for a mixed-methods study. BMJ open. 2020; 10 (9): e039554.

[8] Canbek U, Rosberg DBH, Rosberg HE, Canbek TD, Akgun U, Comert A. The effect of age, BMI, and bone mineral density on the various lumbar vertebral measurements in females. Surgical and radiologic anatomy: SRA. 2021; 43 (1): 101-8.

[9] Dlungwane T, Voce A, Knight S. Prevalence and factors associated with low back pain among nurses at a regional hospital in KwaZulu-Natal, South Africa. Health SA=SA Gesondheid. 2018; 23: 1082.

[10] Chanplakorn P, Wongsak S, Woratanarat P, Wajanavisit W, Laohacharoensombat W. Lumbopelvic alignment on standing lateral radiograph of adult volunteers and the classification in the sagittal alignment of lumbar spine. European spine journal official publication of the European Spine Society, the European Spinal Deformity Society, and the European Section of the Cervical Spine Research Society. 2011; 20 (5): 706-12.

[11] Ogon I, Takashima H, Morita T, Oshigiri T, Terashima Y, Yoshimoto $\mathrm{M}$, et al. Association between Spinopelvic Alignment and Lumbar Intervertebral Disc Degeneration Quantified with Magnetic Resonance Imaging T2 Mapping in Patients with Chronic Low Back Pain. Spine surgery and related research. 2020; 4 (2): 135-41.

[12] Zwierzchowska A, Tuz J, Grabara M. Is BAI better than BMI in estimating the increment of lumbar lordosis for the Caucasian population? Journal of back and musculoskeletal rehabilitation. 2020; 33 (5): 849-55.

[13] Jalai CM, Diebo BG, Cruz DL, Poorman GW, Vira S, Buckland AJ, et al. The impact of obesity on compensatory mechanisms in response to progressive sagittal malalignment. The spine journal: official journal of the North American Spine Society. 2017; 17 (5): 681-8.

[14] de Mello AP, Martins G, Heringer AR, Gamallo RB, Martins Filho L, de Abreu AV, et al. Back pain and sagittal spine alignment in obese patients eligible for bariatric surgery. European spine journal: official publication of the European Spine Society, the European Spinal Deformity Society, and the European Section of the Cervical Spine Research Society. 2019; 28 (5): 967-75.

[15] Schroeder N, Noschenko A, Burger E, Patel V, Cain C, OuYang D, et al. Pelvic Incidence Changes Between Flexion and Extension. Spine deformity. 2018; 6 (6): 753-61.

[16] Wariri O, Alhassan JAK, Mark G, Adesiyan O, Hanson L. Trends in obesity by socioeconomic status among nonpregnant women aged 15-49 y: a cross-sectional, multidimensional equity analysis of demographic and health surveys in 11 sub-Saharan Africa countries, 1994-2015. International health. 2020.

[17] Okafor CI, Gezawa ID, Sabir AA, Raimi TH, Enang O. Obesity, overweight, and underweight among urban Nigerians. Nigerian journal of clinical practice. 2014; 17 (6): 743-9.
[18] Chukwuonye, II, Chuku A, John C, Ohagwu KA, Imoh ME, Isa SE, et al. Prevalence of overweight and obesity in adult Nigerians - a systematic review. Diabetes, metabolic syndrome and obesity: targets and therapy. 2013; 6: 43-7.

[19] Cannata F, Vadala G, Ambrosio L, Fallucca S, Napoli N, Papalia R, et al. Intervertebral disc degeneration: A focus on obesity and type 2 diabetes. Diabetes/metabolism research and reviews. 2020; 36 (1): e3224.

[20] Kieser DC, Wyatt MC, Boissiere L, Hayashi K, Cawley DT, Yilgor $\mathrm{C}$, et al. The effect of increasing body mass index on the pain and function of patients with adult spinal deformity. Journal of spine surgery. 2019; 5 (4): 535-40.

[21] Horn SR, Bortz CA, Ramachandran S, Poorman GW, Segreto F, Siow M, et al. Suboptimal Age-Adjusted Lumbo-Pelvic Mismatch Predicts Negative Cervical-Thoracic Compensation in Obese Patients. International journal of spine surgery. 2019; 13 (3): 252-61.

[22] Hashimoto J, Yoshii T, Sakai K, Hirai T, Yuasa M, Inose H, et al. Impact of body mass index on surgical outcomes and complications in adult spinal deformity. Journal of orthopaedic science: official journal of the Japanese Orthopaedic Association. 2021.

[23] Erick PN, Smith DR. Low back pain among school teachers in Botswana, prevalence and risk factors. BMC musculoskeletal disorders. 2014; 15: 359.

[24] Duan PG, Mummaneni PV, Wang M, Chan AK, Li B, Mayer $\mathrm{R}$, et al. Obesity may be associated with adjacent-segment degeneration after single-level transforaminal lumbar interbody fusion in spinopelvic-mismatched patients with a minimum 2-year follow-up. Journal of neurosurgery Spine. 2020: $1-6$.

[25] Zhang Y, Zhang J, Liu H, Shao Y, He F, Chen A, et al. Impact of obesity on restoration of sagittal balance and clinical efficacy after posterior lumbar interbody fusion. Journal of clinical neuroscience: official journal of the Neurosurgical Society of Australasia. 2019; 69: 170-4.

[26] Dai H, Alsalhe TA, Chalghaf N, Ricco M, Bragazzi NL, Wu J. The global burden of disease attributable to high body mass index in 195 countries and territories, 1990-2017: An analysis of the Global Burden of Disease Study. PLoS medicine. 2020; 17 (7): e1003198.

[27] Onyemaechi NO, Anyanwu GE, Obikili EN, Onwuasoigwe O, Nwankwo OE. Impact of overweight and obesity on the musculoskeletal system using lumbosacral angles. Patient preference and adherence. 2016; 10: 291-6.

[28] Ando K, Kobayashi K, Nakashima H, Machino M, Ito S, Kanbara S, et al. Poor spinal alignment in females with obesity: The Yakumo study. Journal of orthopaedics. 2020; 21: 512-6.

[29] Uysal E, Paksoy Y, Koplay M, Nayman A, Gumus S. Effects of body mass index, mesenteric and abdominal subcutaneous adipose tissue on the spinopelvic parameters. Wiener klinische Wochenschrift. 2015; 127 (23-24): 935-41. 